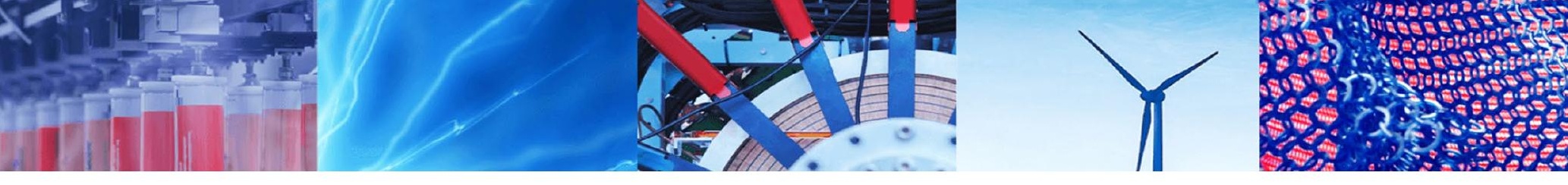

Research Article

\title{
Corrosion inhibition of galvanized steel in hydrochloric acid medium by a physically modified starch
}

\author{
C. K. Anyiam ${ }^{1,3} \cdot$ O. Ogbobe Og. E. Oguzie $^{3} \cdot$ I. C. Madufor ${ }^{2}$. S. C. Nwanonenyi ${ }^{2,3}$. G. C. Onuegbu ${ }^{2} \cdot$ H. C. Obasi $^{2}$. \\ M. A. Chidiebere 3
}

Received: 15 December 2019 / Accepted: 25 February 2020 / Published online: 2 March 2020

(c) Springer Nature Switzerland AG 2020

\begin{abstract}
Native starch extracted from sweet potato tubers was modified via extrusion. The native starch and modified starch were characterized by Fourier transform infrared (FTIR) spectroscopy, which revealed slight modifications in peak position and intensities on starch modification. The modified starch was evaluated as a corrosion inhibitor of galvanized steel in $1 \mathrm{M} \mathrm{HCl}$ solution by gravimetric and potentiodynamic polarization measurement techniques. Results obtained from gravimetric measurement reveals that the modified starch inhibition efficacy was dependent on time, concentration and temperature, increasing with increase in concentration and decreasing with increase in time of immersion and temperature of the system. Maximum inhibition efficiency of $64.26 \%$ was obtained at a concentration of $0.7 \mathrm{~g} / \mathrm{L}$ PMS. Also, result from polarization technique indicated that the modified starch belonged to a mixed-type inhibitor. Adsorption of the inhibitor on the galvanized steel surface was found to obey the Langmuir adsorption isotherm.
\end{abstract}

Keywords Galvanized steel · Hydrochloric acid · Gravimetric measurements · Physically modified starch

\section{Introduction}

Corrosion of metals and alloys occurs due to chemical reactions with their environment, which often results in severe deterioration in the properties of the metal or the material. The preliminary steps to reduce or combat corrosion require the eradication or subdual of the corrosive activity by the use of inhibitors, pigments, coatings, and others providing barrier properties, corrosion reducing activity and overall an active anti-corrosion effect. The use of inhibitors remains one of the most effective, economical, and practical methods of protecting metallic surfaces against corrosion in aggressive media. Owing to the growing interest and attention of the world towards the protection of the environment, corrosion researches are geared towards finding alternative green corrosion inhibitors to replace synthetic corrosion inhibitors which in spite of their high efficiency are expensive, toxic and harmful to the environment when compared to the green corrosion inhibitors [1, 2]. Green polymeric inhibitors are natural biopolymers obtained from plants and animals, and they include starch, lignin, cellulose, cashew nut shell liquid, sucrose, rice husks, caffeic acid, lactic acid, chitosan to mention but a few. Recent studies have focused on the evaluation and development of "environmentally friendly" compounds as corrosion inhibitors, these environmentally corrosion inhibitors include starch [3], pectin [4,5], chitosan $[6,7]$, gum arabic $[8,9]$, honey, glucose, hydroxyethyl cellulose, gellan gum, chitosan. These green polymers comprise functional groups which impart excellent adhesion and corrosion resistant performance to the substrate. They prevent corrosion by being adsorbed on the surface of the substrate and forming a shielding layer, that deters access to corrosive

C. K. Anyiam, chokuim@yahoo.com | 1 Department of Prosthetics and Orthotics Technology, Federal University of Technology, Owerri, Nigeria. ${ }^{2}$ Department of Polymer and Textile Engineering, Federal University of Technology, Owerri, Nigeria. ${ }^{3}$ Electrochemistry and Materials Science Research Laboratory, Department of Chemistry, Federal University of Technology, Owerri, Nigeria. 
species [10-12]. Green polymeric inhibitors of plant origin have become important because they are environmentally acceptable, inexpensive, readily available, and renewable sources of materials. However, the active performance of these biopolymers is further enhanced by modifications [13].

Starch is an eco-friendly polymer obtained from plants with a complex structure made up of regular crystalline regions that are interspersed with loose, amorphous regions. These regions instill their varying characteristics in the unique molecular structure of starch, enhancing or limiting its scope of application [14]. Sweet potato starch is composed of a mixture of amylose and amylopectin and is reported to possess A-type (high swelling) pattern, and it's starch granules are medium sized with a smooth round, oval shape [15]. Native starch displays some shortcomings that restrict its use, such as insolubility in cold water and sensitivity to shearing and low $\mathrm{pH}$ [16]. The modification of starch could circumvent these limitations. Starch modification alters the physicochemical characteristics of native starch to enhance functional features. Several methods have been developed to modify the starch polymer to make it highly flexible and thus, changing its physicochemical properties and structural attributes to increase its value for food and non-food industries [17]. Starch with less extensive crystalline regions improved physicochemical properties, and increased reactivity is often preferred for functional purposes. Consequently, there is great interest in ways to alter the structure in the crystalline region or reduce the size of the crystalline regions $[18,19]$. The methods of decreasing starch crystalline regularity include drying such as extrusion, drum drying or spray drying, enzymatic degradation processes [20,21], chemical processes, such as acidolysis, oxidation [22], and physical processes, such as heat-moisture treatment, radioactive degradation, microwave degradation, ultrasonic degradation and extrusive degradation processes.). A number of studies have focused on the corrosion inhibition performance of native starches [7, 23], modified starches $[9,24-29]$ and synergistic studies of starch with other compounds $[3,30]$.

Corrosion is a phenomenon that affects all metals, galvanised steel undergoes corrosion This work studies the effect of physical modification of sweet potato starch and the inhibition efficacy of the modified sweet potato starch on galvanised steel corrosion in hydrochloric acid solution using gravimetric and potentio-dynamic polarization techniques.

\section{Materials and methods}

\subsection{Materials}

Native starch extracted from Sweet Potato (Ipomoeabatatas) grown in South Eastern, Nigeria was modified using a laboratory extruder (Brabender) as described by Della Valle and Vergnes [31] in the Electrochemistry and Materials Science Research Laboratory, FUTO.

Galvanized sheet (type GP grade $O$ and purity $98 \%$ with composition of $\mathrm{C} \leq 0.14, \mathrm{P} \leq 0.02, \mathrm{Mn} \leq 0.2, \mathrm{Ti} \leq 0.036$, $\mathrm{Si} \leq 0.008$ and the remainder $\mathrm{Zn}$ and $\mathrm{Fe}$ ) used were presscut mechanically into $3 \mathrm{~cm} \times 3 \mathrm{~cm} \times 0.2 \mathrm{~cm}^{3}$ coupons and polished with fine emery papers. The coupons were cleaned with acetone, washed with double-distilled water, dried in hot air, weighed and kept in a desiccator for corrosion test.

Hydrochloric acid (BDH, analytical reagent grade) and double distilled water were used to prepare the $1 \mathrm{M} \mathrm{HCl}$ solutions used as corrodent (or blank acid solution) for the corrosion test. The inhibitor solutions containing PMS were carefully prepared within the concentration range of $0.1-0.7 \mathrm{~g}$ in $1 \mathrm{~L}$ of $1 \mathrm{M} \mathrm{HCl}$.

\subsection{Fourier transform infrared spectroscopy}

Fourier Transform Infrared Spectroscopy was used to obtain the spectra of native potato starch and physically modified potato starch (PMS) at a frequency of 4000 to $400 \mathrm{~cm}^{-1}$.

\subsection{Gravimetric measurement}

The polished and pre-weighed galvanized steel coupons of uniform size were suspended with glass rods and hooks in $250 \mathrm{ml}$ beakers containing $200 \mathrm{ml}$ of the test solutions at room temperature of $30 \pm 1{ }^{\circ} \mathrm{C}$. The reaction time increased progressively by $24 \mathrm{~h}$ up to $120 \mathrm{~h}$ of immersion. Also, to study the effect of temperature variations, the beakers were equilibrated at $30-60^{\circ} \mathrm{C}$ in a thermostatic water bath and the coupons retrieved at 8-h interval in line with ASTM G1-90. The coupons were retrieved at fixed time intervals and cleaned thoroughly, following standard procedures. The difference in weight $(\Delta W)$ of the coupons before and after immersion in different test solutions were obtained in triplicates and the average taken as the weight loss, which was then used to calculate the corrosion rate $(\mathrm{CR})$ using the Eq. (1):

$\mathrm{CR}=\frac{\Delta \mathrm{W} \times 87600}{\mathrm{DAT}}$

where $C R$ is the corrosion Rate $(\mathrm{mm} / \mathrm{y}), \Delta \mathrm{W}$ is the change in weight $(\mathrm{g}), \mathrm{D}$, the density of the coupon $\left(\mathrm{g} / \mathrm{cm}^{3}\right), A$ is the area of the exposed surface of the coupon $\left(\mathrm{cm}^{2}\right)$ and $T$ is the time of immersion (h).

The inhibitor efficiency was measured using the equation: 


$$
(\% \mathrm{IE})=\frac{\mathrm{CR}_{\mathrm{o}}-\mathrm{CR}_{\mathrm{i}}}{\mathrm{CR}_{\mathrm{o}}} \times 100
$$

where $\mathrm{CR}_{\mathrm{o}}=$ corrosion rate of galvanized steel in blank corrodent; $C \mathrm{CR}_{\mathrm{i}}=$ corrosion rate of galvanized steel in presence of the inhibitor.

\subsection{Potentiodynamic polarization measurement}

The potentiodynamic polarization study was carried out using a conventional glass electrolytic cell and PARC2273 advanced electrochemical instrument. The glass cell assembly consists of electrodes (reference electrode-saturated calomel electrode, the counter electrode-platinum wire, and working electrode-galvanized steel coupon), electrolytes, and copper wire. The metal electrodes were connected to copper wire for electrical contact and embedded in epoxy resin, leaving an uncovered surface area. Before each polarization measurement, a stabilization period of $30 \mathrm{~min}$ was allowed for a steady state open circuit potential (OCP). Polarization measurements over a potential range of -250 to $+250 \mathrm{mV}$ with respect to OCP with a scan rate of $0.333 \mathrm{mV} / \mathrm{s}$ were made. The experiment was carried out in triplicate, and the average values of corrosion parameters reported. The tests were performed using a scan rate of $0.166 \mathrm{~m} \mathrm{V/S}$, commencing at a potential above $250 \mathrm{mV}$ more active than the stable open circuit potential in the absence and presence of PMS. All the tests were carried out at room temperature $\left(30 \pm 1^{\circ} \mathrm{C}\right)$.

\section{Results and discussion}

\subsection{FTIR characterization of unmodified and modified potato starch}

Figure 1 presents the FTIR spectra for native starch and physically modified starch. The FTIR spectra of the unmodified (native) starch showed complex vibrational modes due to the pyranose ring of the glycosidic unit in the region below $800 \mathrm{~cm}^{-1}$ which is in line with reports of Kizil and Seetharaman [31]. At the $1000-1200 \mathrm{~cm}^{-1}$ region, the characteristic features of polysaccharides were observed. The region was dominated by ring vibrations overlapped by stretching vibrations of $\mathrm{C}-\mathrm{OH}$ side groups and the $\mathrm{C}-\mathrm{O}-\mathrm{C}$ glycosidic bond vibration [32]. Within this wave number range, the $\mathrm{C}-\mathrm{O}$ and $\mathrm{C}-\mathrm{C}$ stretching vibrations contribute to modes related to the bands at 994 , 1084 , and $1163 \mathrm{~cm}^{-1}$ and the C-O-C glycosidic band at $860 \mathrm{~cm}^{-1}$. The spectrum also displays $\mathrm{C}-\mathrm{H}$ bending bands at 1465,1425 , and $1366 \mathrm{~cm}^{-1}$. The starch spectrum shows characteristic $\mathrm{O}-\mathrm{H}$ bending and stretching bands at 1649 and $3430 \mathrm{~cm}^{-1}$, respectively which is attributed to the complex vibrational stretches associated with free intermolecular and intra molecular bound hydroxyl groups that make up the gross structure of starch [33]. Characteristic peaks were observed at $2929 \mathrm{~cm}^{-1}$ for C-H stretches associated with the ring hydrogen atoms. The spectrum of the physically modified starch is also presented in Fig. 1. From the spectra, it is observed that there are slight shifts in the peaks, reductions in the intensity of the peaks at $1350-1353 \mathrm{~cm}^{-1}$, and broadening of the $\mathrm{O}-\mathrm{H}$ band at $3430 \mathrm{~cm}^{-1}$. At the $1022 \mathrm{~cm}^{-1}$ wavenumber, which denotes the starch amorphous region, a broader band is observed indicating increase in the amorphous region of the starch
Fig. 1 FTIR spectra of sweet potato native starch (1), and physically modified starch (2)

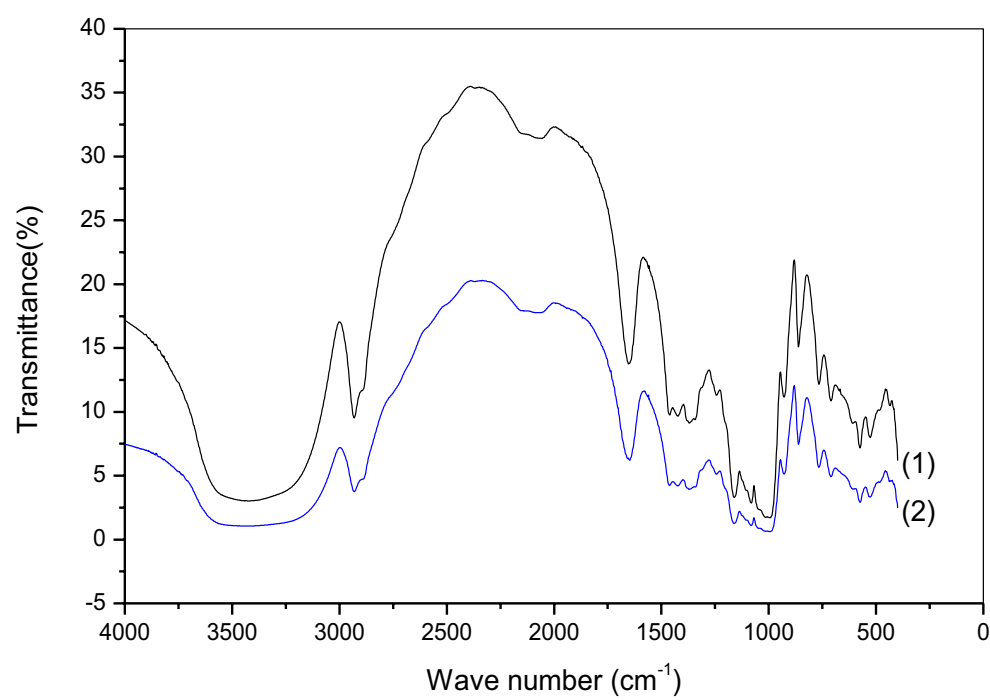

SN Applied Sciences A SPRINGER NATURE journa 
Table 1 Calculated value of corrosion rate and inhibition efficiency of galvanized steel in $1 \mathrm{M} \mathrm{HCl}$ in the presence and absence of PMS at varying time

\begin{tabular}{|c|c|c|c|c|c|c|c|c|c|c|}
\hline \multirow[t]{2}{*}{ Conc $(g / L)$} & \multicolumn{5}{|c|}{ Corrosion rate $(\mathrm{mm} / \mathrm{y})$} & \multicolumn{5}{|c|}{ Inhibition efficiency (\%) } \\
\hline & $24 \mathrm{~h}$ & $48 \mathrm{~h}$ & $72 \mathrm{~h}$ & $96 \mathrm{~h}$ & $120 \mathrm{~h}$ & $24 \mathrm{~h}$ & $48 \mathrm{~h}$ & $72 \mathrm{~h}$ & $96 \mathrm{~h}$ & $120 \mathrm{~h}$ \\
\hline Blank & 53.56 & 33.48 & 23.59 & 18.49 & 15.50 & - & - & - & - & - \\
\hline 0.1 & 37.83 & 24.02 & 17.53 & 14.39 & 12.47 & 29.40 & 28.30 & 25.70 & 22.20 & 19.50 \\
\hline 0.3 & 34.50 & 22.63 & 16.47 & 13.12 & 11.15 & 35.60 & 32.40 & 30.20 & 29.00 & 28.10 \\
\hline 0.5 & 26.82 & 17.94 & 12.78 & 10.42 & 9.06 & 49.90 & 46.70 & 45.80 & 43.60 & 41.60 \\
\hline 0.7 & 19.14 & 15.94 & 11.51 & 9.28 & 8.30 & 64.30 & 62.40 & 51.20 & 49.80 & 46.50 \\
\hline
\end{tabular}

which could be as a result of the shearing force the starch granules have to pass through during extrusion, which is in line with reports by other researchers $[34,35]$.

\subsection{Gravimetric measurement result}

\subsubsection{Effect of time and concentration on corrosion rates and inhibition efficiency}

Table 1 presents the time-dependent gravimetric data for corrosion rate and inhibition efficiency of galvanized steel in the presence and absence of the physically modified starch (PMS). The results indicate that corrosion rate was reduced in the presence of PMS, and this effect became more pronounced with increasing PMS concentration indicating that more inhibitor molecules were adsorbed on the steel surface that led to the formation of a protective film thus inhibiting the dissolution of galvanized steel. The behaviour implies that PMS inhibited galvanized steel corrosion in $1 \mathrm{M} \mathrm{HCl}$, in a concentration-dependent manner and agrees with earlier studies observed by Mobin et al. [3]. It was also observed that corrosion rates decreased with an increase in exposure time. Figures 2 and 3 presents the variation of corrosion rate and inhibition efficiency of different concentrations of PMS at different exposure intervals. Inhibition efficiency generally increased as the concentration of PMS was raised from 0.1 to $0.7 \mathrm{~g} / \mathrm{L}$, but decreased with an increase in immersion time. It was also noted that PMS exhibited a maximum inhibition efficiency of $64.26 \%$ at a concentration of $0.7 \mathrm{~g} / \mathrm{L}$ PMS.

\subsection{Adsorption considerations}

The adsorption mechanism for a given inhibitor depends on various factors $[36,37]$ that regulate the mode of adsorption on the metal surface. It is evident that the controlling action of inhibitors on the corroding metal surface in an unfavourable medium occurs by physical or chemical adsorption which involves the replacement of one or more water molecules adsorbed at the metal surface by the inhibitor species [38] as observed in Eq. (3):

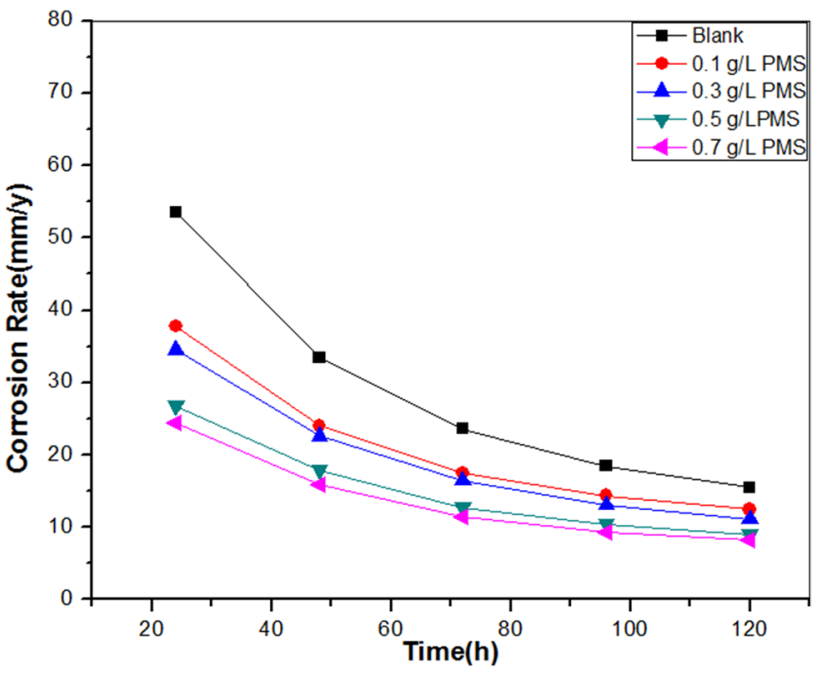

Fig. 2 Corrosion rate against time for galvanized steel in $1 \mathrm{M} \mathrm{HCl}$ in the presence and absence of physically modified starch

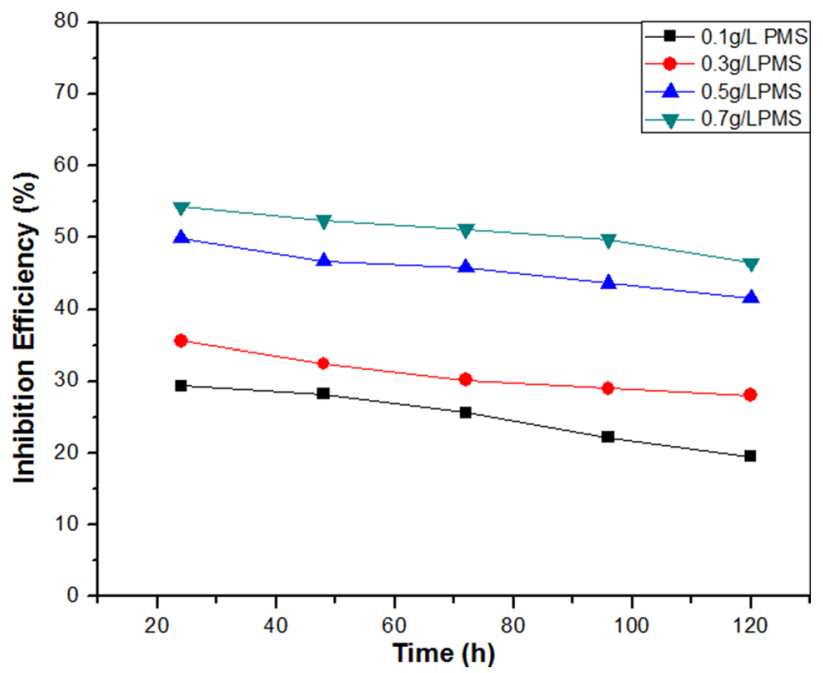

Fig. 3 Inhibition efficiency against time for galvanized steel in $1 \mathrm{M}$ $\mathrm{HCl}$ in the presence and absence of physically modified starch 


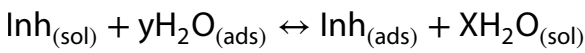

where $\operatorname{lnh}_{(\text {(sol) }}, \operatorname{lnh}_{(\mathrm{ads})}, \mathrm{H}_{2} \mathrm{O}_{\text {(ads) }}$ and represent the inhibitor molecules in the aqueous solution, adsorbed inhibitor molecules, water molecules on the metal surface and water molecules replaced by the inhibitor molecules respectively. To further understand the nature of adsorption, theoretical fitting on different isotherms were carried out using the values of degree of surface coverage obtained from the gravimetric results to determine the best fit. Hence, the degree of surface coverage $\theta$ was evaluated according to Eq. (4) stated below.

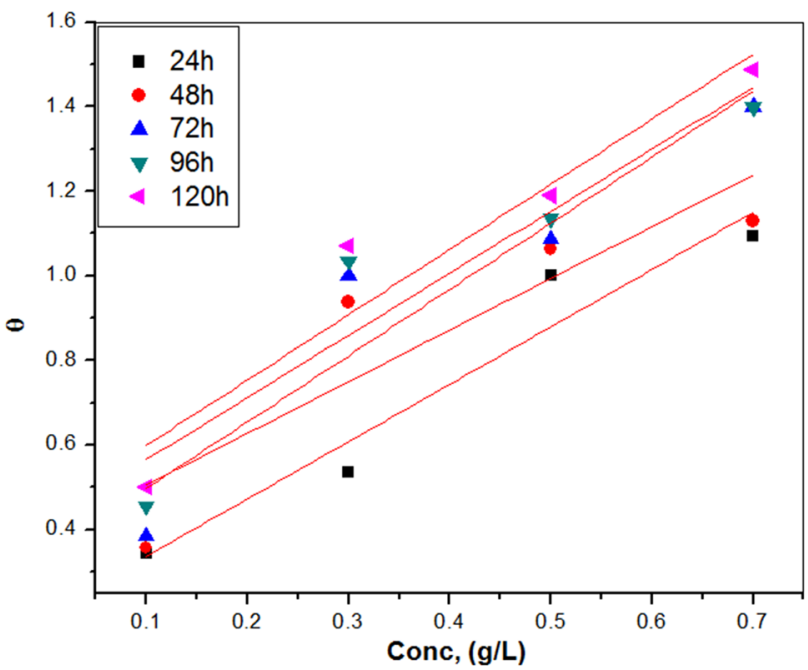

Fig. 4 Langmuir adsorption isotherm for PMS adsorption on galvanized steel in $1 \mathrm{M} \mathrm{HCl}$ solution at $30^{\circ} \mathrm{C}$
$\theta=\frac{\mathrm{CR}_{\mathrm{o}}-\mathrm{CR}_{\mathrm{i}}}{\mathrm{CR}_{\mathrm{o}}}$

where $\mathrm{CR}_{\mathrm{o}}$ is the corrosion rate of galvanized steel in blank corrodent and $\mathrm{CR}_{\mathrm{i}}=$ corrosion rate of galvanized steel in the presence of the inhibitor. The nature of adsorption of PMS on the galvanized steel surface was determined by theoretical fitting carried out on different isotherms, and the correlation coefficients $\left(R^{2}\right)$ were used to define the best fit, which was obtained with Langmuir adsorption isotherm which characterizes physisorption and is given by Eq. (5):

$\frac{C}{\theta}=\frac{1}{\mathrm{~K}_{\mathrm{ads}}}+\mathrm{C}$

where $C$ is inhibitor concentration in $\mathrm{g} / \mathrm{L}, \mathrm{K}_{\mathrm{ads}}$ is the equilibrium adsorption constant and $\theta$ is the degree of surface coverage (Fig. 4).

The Langmuir, Temkin and Freundlich adsorption isotherm parameters obtained from the plots are shown in Table 2, and the correlation coefficients $\left(R^{2}\right)$ were used to determine the best fit, which was obtained with the Langmuir isotherm $\left(R^{2}=0.912\right)$. The Langmuir adsorption isotherm plot is characterized by the value of slope which is above one as well as positive and higher values of $\mathrm{K}_{\mathrm{ads}}$ which represent the adsorption strength and thus suggest more efficient adsorption and hence better inhibition efficiency. $K_{a d s}$ is observed to decrease with increasing immersion time, which denotes desorption of the adsorbed inhibitor, and this is in line with the mechanism of physical adsorption as observed by other researchers $[3,8]$.
Table 2 Calculated values of Langmuir, Temkin, and Freundlich adsorption isotherms for galvanized steel corrosion in $1 \mathrm{M} \mathrm{HCl}$ solution in the different concentrations of PMS at varying time

\begin{tabular}{|c|c|c|c|c|c|c|}
\hline Time (h) & Slope & $\mathrm{R}^{2}$ & Intercept & $\mathrm{K}_{\mathrm{ads}}$ & $\Delta \mathrm{G}_{\mathrm{ads}}\left(\mathrm{kJ} \mathrm{\textrm {mol } ^ { - 1 } )}\right.$ & Isotherm models \\
\hline 24 & 1.221 & 0.912 & 0.202 & 4.951 & -14.147 & Langmuir \\
\hline 48 & 1.356 & 0.701 & 0.351 & 2.849 & -12.756 & \\
\hline 72 & 1.469 & 0.845 & 0.384 & 2.604 & -12.529 & \\
\hline 96 & 1.526 & 0.858 & 0.419 & 2.387 & -12.310 & \\
\hline 120 & 1.543 & 0.888 & 0.445 & 2.247 & -12.158 & \\
\hline 24 & 0.383 & 0.734 & 0.637 & 0.190 & -5.934 & Temkin \\
\hline 48 & 0.368 & 0.656 & 0.606 & 0.192 & -5.969 & \\
\hline 72 & 0.304 & 0.768 & 0.533 & 0.173 & -5.701 & \\
\hline 96 & 0.326 & 0.837 & 0.523 & 0.550 & -6.076 & \\
\hline 120 & 0.323 & 0.894 & 0.499 & 0.532 & -6.226 & \\
\hline 24 & 0.385 & 0.826 & -0.178 & 0.837 & -9.086 & Freundlich \\
\hline 48 & 0.384 & 0.746 & -0.203 & 0.816 & -8.941 & \\
\hline 72 & 0.362 & 0.817 & -0.256 & 0.774 & -8.634 & \\
\hline 96 & 0.422 & 0.837 & -0.255 & 0.775 & -8.639 & \\
\hline 120 & 0.458 & 0.800 & -0.267 & 0.766 & -8.570 & \\
\hline
\end{tabular}


To further clarify the nature of the adsorption, the free energy of adsorption ( $\Delta \mathrm{G}_{\mathrm{ads}}$ ) was calculated using the relation shown below:

$\mathrm{K}_{\mathrm{ads}}=\frac{1}{55.5} \exp \left(-\frac{\Delta \mathrm{G}_{\mathrm{ads}}}{\mathrm{RT}}\right)$

where $K_{a d s}$ is the equilibrium constant for the adsorption process, $\mathrm{R}$ is universal gas constant, $\mathrm{T}$ is the temperature in K. Langmuir's isotherm accounts for the surface coverage by balancing the relative rates of adsorption and desorption, Temkin isotherm considers the effect of indirect adsorbate/adsorbate interactions on the adsorption process while Freundlich isotherm considers the adsorption processes that occur on heterogenous surfaces. Hence, $\mathrm{K}_{\mathrm{ads}}$ values obtained from these isotherms accounts for the inconsistencies in the values of $\Delta \mathrm{G}_{\mathrm{ads}}$ obtained. The free energy of adsorption $\left(\Delta \mathrm{G}_{\mathrm{ads}}\right)$ values presented in Table 2 reveals values lower than $-20 \mathrm{~kJ} \mathrm{~mol}^{-1}$ which confirms physical adsorption as a mode of adsorption. Also, it further implies that the adsorption of PMS on the galvanized steel surface is allowed from the viewpoint of thermodynamics and also indicates strong adsorption of the inhibitor onto the steel surface.

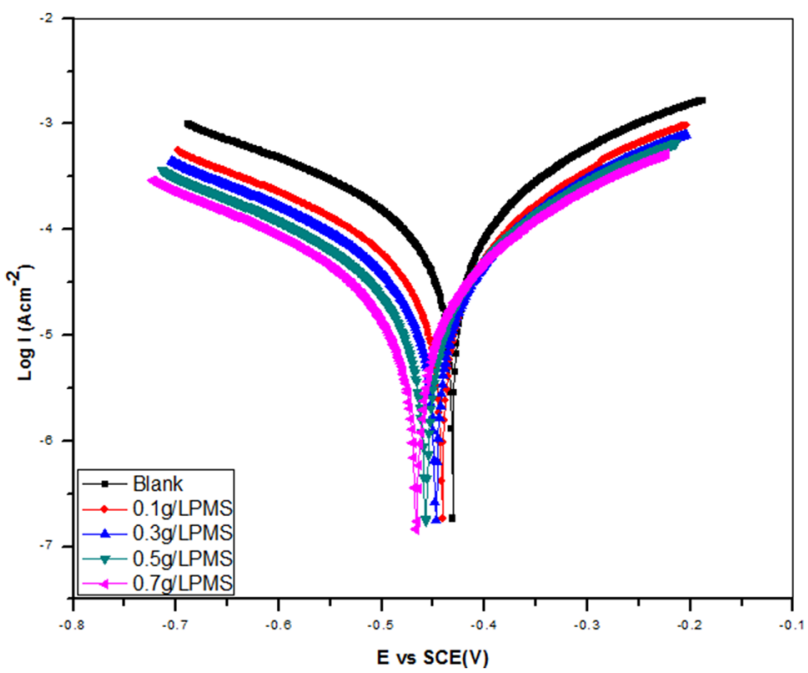

Fig. 5 Polarization curves of galvanized steel corrosion in $1 \mathrm{M} \mathrm{HCl}$ solution without and with PMS

\subsection{Potentiodynamic polarization data}

Potentiodynamic polarization measurements were carried out to acquire further understandings of the inhibiting effect of PMS and from an electrochemical perspective. Figure 5 shows typical polarization curves for the corrosion of galvanized steel sample in $1 \mathrm{M} \mathrm{HCl}$ acid solution without and with different concentrations of PMS. The galvanized steel sample is seen to dissolve briskly with no distinctive shift to passivation within the studied potential range in all environments. Reports in literature show that when shift in Ecorr is strictly above $85 \mathrm{mV}$ or strictly below $85 \mathrm{mV}$, the inhibitor can be regarded as cathodic or anodic type inhibitor respectively, and if the displacement in Ecorr is less than $\pm 85 \mathrm{mV}$ the inhibitor can be seen as mixed type [39-41].

The polarization curves show that PMS repressed the kinetics of both the anodic and cathodic reactions, reducing the corrosion current density $\left(i_{\text {corr }}\right)$. Also, the plots further revealed the mechanisms of action for PMS caused a very slight shift of corrosion potential $\left(\mathrm{E}_{\text {corr }}\right)$ towards cathodic values and inhibited both the cathodic and anodic reactions, with a more pronounced effect on the cathodic hydrogen ion reduction reaction $\left(2 \mathrm{H}^{+}+2 \mathrm{e} \rightarrow \mathrm{H}_{2}\right)$. In other words, PMS functioned as a mixed-type inhibitor, with predominant cathodic influence. The polarization parameters obtained from the polarization curves are presented in Table 3. The values of the corrosion current density in the absence and presence of inhibitor were used to estimate the inhibition efficiency from polarization data and presented in Table 3 below. The data reveals that the values of the $\mathrm{E}_{\text {corr }}$ shifted more towards negative values as the concentration of PMS increased, and corrosion current densities and numerical values of cathodic and anodic Tafel slopes demonstrated marked increment on the addition of PMS. Hence, the degree of increase is dependent on the concentration of the PMS inhibitor.

\subsection{Temperature effect}

The effect of temperature on the adsorption of the PMS inhibitor on the galvanized steel surface in acidic media was investigated. The calculated values of corrosion rates and inhibition efficiency for PMS at different
Table 3 Potentiodynamicpolarization parameters for galvanized steel corrosion in $1 \mathrm{M} \mathrm{HCl}$ at different concentrations of PMS at $30^{\circ} \mathrm{C}$

\begin{tabular}{llllll}
\hline System & $\mathrm{E}_{\text {corr }} \mathrm{E}(\mathrm{mV}(\mathrm{SCE}))$ & $\mathrm{I}_{\text {corr }}\left(\mu \mathrm{Acm}{ }^{-2}\right)$ & $\mathrm{IE}(\%)$ & $\mathrm{b}_{\mathrm{c}}\left(\mathrm{mVdec}^{-1}\right)$ & $\mathrm{b}_{\mathrm{a}}\left(\mathrm{mVdec}^{-1}\right)$ \\
\hline Blank & -436.67 & 360 & - & 65 & 51 \\
$0.1 \mathrm{~g} / \mathrm{L}$ PMS & -446.43 & 258.7 & 28.13 & 80 & 56 \\
$0.3 \mathrm{~g} / \mathrm{L}$ PMS & -449.35 & 235.7 & 34.54 & 84 & 58 \\
$0.5 \mathrm{~g} / \mathrm{L}$ PMS & -456.24 & 191.8 & 46.73 & 89 & 61 \\
$0.7 \mathrm{~g} / \mathrm{L}$ PMS & -462.09 & 142.4 & 60.44 & 95 & 64 \\
\hline
\end{tabular}


concentrations and temperature range $\left(35-65^{\circ} \mathrm{C}\right)$ were investigated and are presented in Table 4. From Table 4, it is evident that the corrosion rates are reduced in the presence of starch as compared to the free acid solution. However, the rate of corrosion increased with an increase in temperature at all concentrations, which indicates physical adsorption of the PMS molecules on the galvanized steel. Kinetic parameters such as free energy of adsorption, $\left(\Delta \mathrm{G}_{\mathrm{ads}}\right)$, enthalpy of adsorption, $\left(\Delta \mathrm{H}_{\mathrm{ads}}\right)$, and the entropy of adsorption $\left(\Delta \mathrm{S}_{\mathrm{ads}}\right)$ and energy of activation $\left(E_{a}\right)$ were determined. Analysis of the temperature dependence of inhibition efficiency as well as evaluation of corrosion apparent activation energies with and without the inhibitor defines the probable mechanism of inhibitor adsorption. A decline in inhibition efficiency with the rise in temperature with the analogous rise in corrosion activation energy in the presence of inhibitor compared to its absence is often interpreted as being indicative of the formation of a physically adsorbed film. The contrary effect, which is an increase in inhibition efficiency with the rise in temperature and lower activation energy in the presence of inhibitor, suggests chemisorption [42-44]. The temperature effect on the inhibited acid-metal reaction is very multifaceted as many changes ensue on the metal surface, such as reorganization and breakdown of the inhibitor, desorption of inhibitor and swift etching $[45,46]$.

\subsubsection{Energy of activation (Ea)}

The corrosion of metals in uninhibited or inhibited solution is an electrochemical reaction that involves the energy of activation which initiates the process and aids in determining the mechanism of inhibition adsorption as inferred by Oguzie et al. [12]. The corrosion rate relates to the energy of activation via the Arrhenius Eq. (7):

$\log C R=\log A-\frac{E_{a}}{2.303 R T}$

where $C R$ is the corrosion rate, $A$ is the pre-exponential factor, Ea is the energy of activation, $\mathrm{T}$ is the absolute temperature, and $\mathrm{R}$ is the universal gas constant. The plots of the logarithm of corrosion rate versus the inverse of absolute temperature for the galvanized steel in $1 \mathrm{M} \mathrm{HCl}$ is presented in Fig. 6 . The calculated values of $E_{a}$ obtained from the slope $\left(-E_{a} / 2.303 R\right)$ is also presented in Table 5. The energy of activation values (Ea) obtained was observed to be higher in the inhibited solutions compared to the uninhibited solutions, inferring that high values of Ea entail low corrosion rate, whereas small values of Ea results in a high rate of corrosion. The variations in Ea values observed may be linked to the modification of the mechanism of corrosion process in the presence of adsorbed PMS species which substantiates the existence of increased energy barrier for the galvanized steel dissolution process. It could be deduced from the observed increase in Ea values of the inhibited solution that increase in the inhibitor concentration results in enhanced adsorbed inhibitor molecules on the galvanized steel surface [47]. Also, this behaviour protective action primarily occurred through physical adsorption of PMS species on the galvanized steel surface with the deactivation of these surfaces to hydrogen $\left(\mathrm{H}_{2}\right)$ atom recombination [24]. It is evident from data listed in Table 5 that the range of $E_{a}$ values (30.93-39.42 $\mathrm{kJ} / \mathrm{mol}$ ) is lower than the limit value of $80 \mathrm{~kJ} / \mathrm{mol}$ required for chemical

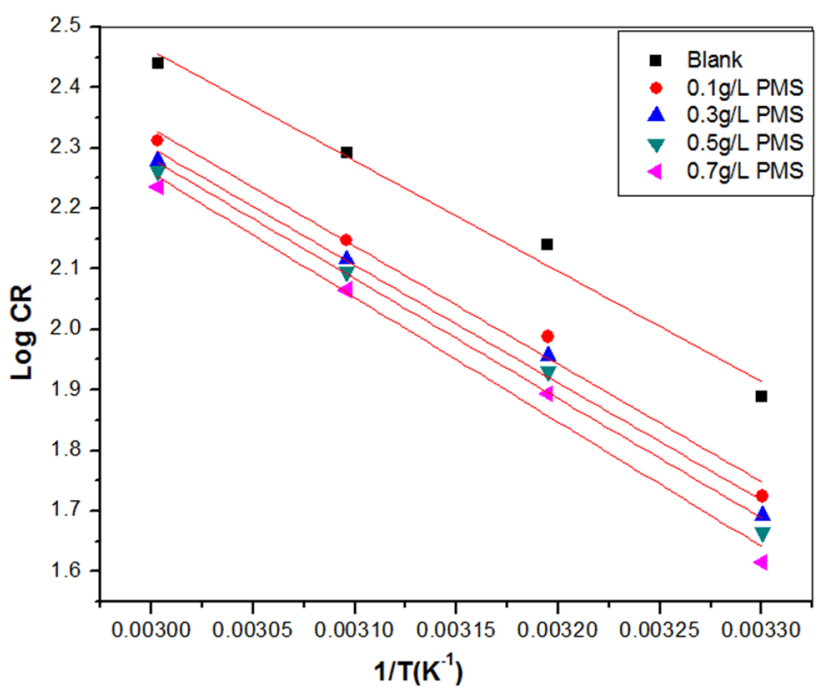

Fig. 6 Log CR versus $1 / T$ for the corrosion of galvanized steel in $1 M$ $\mathrm{HCl}$ in the absence and presence of PMS
Table 4 Calculated value of corrosion rate and inhibition efficiency of galvanized steel in $1 \mathrm{M} \mathrm{HCl}$ in the presence and absence of PMS at varying temperatures $\left(35-65^{\circ} \mathrm{C}\right)$

\begin{tabular}{|c|c|c|c|c|c|c|c|c|}
\hline \multirow[t]{2}{*}{ Conc. (g/L) } & \multicolumn{4}{|c|}{ Corrosion rate (mm/yr) } & \multicolumn{4}{|c|}{ Inhibition efficiency (\%) } \\
\hline & $35^{\circ} \mathrm{C}$ & $45^{\circ} \mathrm{C}$ & $55^{\circ} \mathrm{C}$ & $65^{\circ} \mathrm{C}$ & $35^{\circ} \mathrm{C}$ & $45^{\circ} \mathrm{C}$ & $55^{\circ} \mathrm{C}$ & $65^{\circ} \mathrm{C}$ \\
\hline Blank & 87.53 & 161.3 & 207.3 & 289.7 & - & - & - & - \\
\hline 0.1 & 55.12 & 111.5 & 156.1 & 229.7 & 37.03 & 30.90 & 24.71 & 20.70 \\
\hline 0.3 & 50.77 & 102.1 & 146.7 & 212.8 & 42.00 & 36.72 & 29.22 & 26.55 \\
\hline 0.5 & 40.79 & 84.84 & 122.5 & 182.1 & 53.39 & 47.41 & 40.93 & 37.15 \\
\hline 0.7 & 35.08 & 74.01 & 105.8 & 155.9 & 59.92 & 54.12 & 48.94 & 46.19 \\
\hline
\end{tabular}


Table 5 Kinetic parameters for dissolution of galvanized steel in $1 \mathrm{M} \mathrm{HCl}$ in the absence and presence of PMS at different temperatures

\begin{tabular}{llcllllll}
\hline Conc. $\mathrm{g} / \mathrm{L}$ & $\Delta \mathrm{H}_{\mathrm{ads}}(\mathrm{KJ} / \mathrm{mol})$ & $\Delta \mathrm{S}_{\mathrm{ads}}(\mathrm{J} / \mathrm{mol})$ & $\mathrm{E}_{\mathrm{a}}(\mathrm{KJ} / \mathrm{mol})$ & \multicolumn{4}{l}{$\Delta \mathrm{G}_{\mathrm{ads}}(\mathrm{KJ} / \mathrm{mol})$} \\
\cline { 5 - 8 } & & & & & $35{ }^{\circ} \mathrm{C}$ & $45^{\circ} \mathrm{C}$ & $55^{\circ} \mathrm{C}$ & $65^{\circ} \mathrm{C}$ \\
\hline Blank & 28.29 & -101.90 & 30.928 & - & - & - & - \\
0.1 & 32.55 & -98.69 & 35.191 & -14.822 & -14.579 & -14.194 & -13.983 \\
0.3 & 34.64 & -97.33 & 37.282 & -12.542 & -12.363 & -12.084 & -11.811 \\
0.5 & 35.25 & -94.53 & 37.893 & -12.408 & -12.177 & -11.843 & -11.757 \\
0.7 & 36.77 & -91.54 & 39.420 & -12.228 & -11.999 & -11.810 & -11.860 \\
\hline
\end{tabular}

adsorption. The scenario thus concludes that the adsorption is physical adsorption.

\subsubsection{Entropy of adsorption $\left(\Delta \mathrm{S}_{\mathrm{ads}}\right)$ and enthalpy of adsorption $\left(\Delta \mathrm{H}_{\mathrm{ads}}\right)$}

The entropy of adsorption $\left(\Delta \mathrm{S}_{\text {ads }}\right)$ and enthalpy of adsorption $\left(\Delta \mathrm{H}_{\mathrm{ads}}\right)$ were used to characterize the adsorption mechanism and thermodynamic process of the corrosion inhibition. A negative value of $\Delta \mathrm{S}_{\mathrm{ads}}$ reflects the free movement of inhibitor molecules in the bulk solution and the reduction in the disorderly manner of the adsorption of inhibitor molecules on the metal surface while the positive value of $\Delta \mathrm{S}_{\mathrm{ads}}$ indicates an increase in the degree of disorderliness of corrosion inhibition system in the presence of inhibitor [23]. Positive enthalpy value in both the free acid and inhibited solutions infers that the dissolution of metals occurred by the endothermic process, while negative values assume an exothermic process. Furthermore, the increase in enthalpy values in the presence of inhibitor compared to the blank acid solution indicates physical adsorption. The estimated values of entropy and enthalpy of adsorption for the corrosion inhibition process was calculated from the transition-state Eq. (8):

$\mathrm{CR}=\frac{\mathrm{RT}}{\mathrm{Nh}} \exp \left(\frac{\Delta \mathrm{S}_{\mathrm{ads}}}{\mathrm{R}}\right) \exp \left(-\frac{\Delta \mathrm{H}_{\mathrm{ads}}}{\mathrm{RT}}\right)$

where $\Delta \mathrm{S}_{\mathrm{ads}}$ and $\Delta \mathrm{H}_{\mathrm{ads}}$ are entropy and enthalpy of the adsorption process, respectively; $C R$ is corrosion rate; $R$, molar gas constant, $\mathrm{T}$ is the absolute temperature, $\mathrm{N}$ is the Avogadro's number, $\mathrm{h}$ is the Planck's constant. Linear plot of $\log (\mathrm{CR} / \mathrm{T})$ versus $1 / \mathrm{T}$ for a blank and inhibited solution is shown in Fig. $7, \Delta \mathrm{S}_{\mathrm{ads}}$ and $\Delta \mathrm{H}_{\mathrm{ads}}$ were calculated from the intercept $[(\log (\mathrm{R} / \mathrm{Nh})+\Delta \mathrm{Sads} / 2.303 \mathrm{R})$ and slope $(-\Delta$ Hads/2.303R) respectively and are presented in Table 5 .

The negative values of entropy of activation $\Delta S$ obtained show that the activated complex in the rate determining step characterizes an association rather than a dissociation step, inferring that a decrease in disorder takes place moving from reactants to the activated complex. Also, it is observed that $\Delta \mathrm{S}$ increased in the PMS inhibited system compared to uninhibited system. The

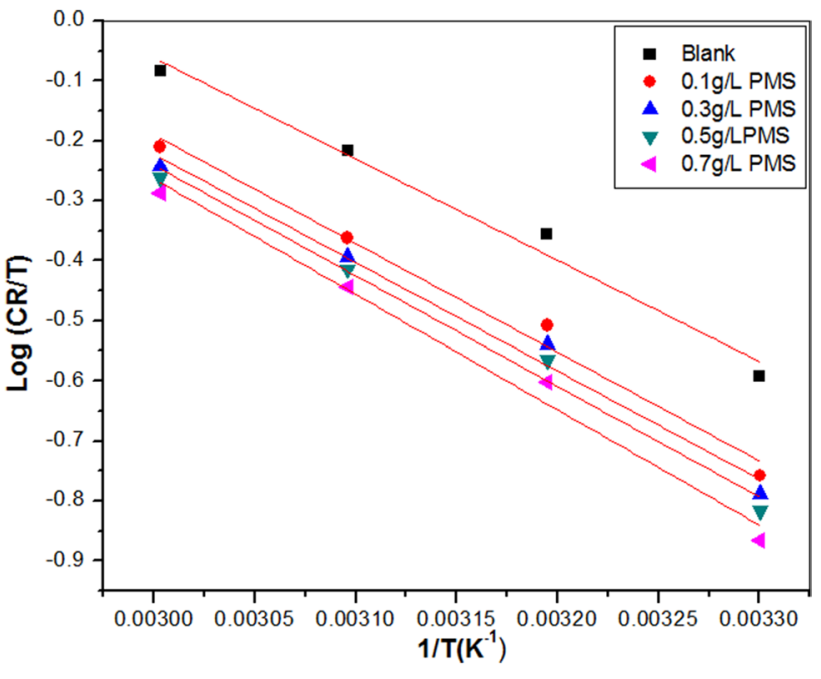

Fig. 7 Log $C R / T$ versus $1 / T$ for the corrosion of galvanized steel in $1 \mathrm{MHCl}$ acid solution in the absence and presence of PMS

observation could be explained thus; in the uninhibited system, the transition state of the rate determining recombination step denotes a more orderly arrangement relative to the initial state, so a high value of $\Delta S$ is obtained. In the presence of PMS inhibitor, the surface is covered with inhibitor molecules, which retards the discharge of hydrogen ions at the metal surface, causing an increase in the entropy of activation. The increase of $\Delta S(-101.90$ to $-91.54 \mathrm{~J} / \mathrm{mol}$ ) with increasing inhibitor concentration reiterates the fact that an increase in disorder takes place from the reactant to the activated complex. The positive values of $\Delta \mathrm{H}(+28.29$ to $+36.77 \mathrm{~kJ} / \mathrm{mol})$ reveal the endothermic nature of galvanized steel dissolution in both inhibited and uninhibited systems. The increase in $\Delta \mathrm{H}$ with increasing inhibitor concentration discloses the effect of activation kinetic parameters in the corrosion of galvanized steel [38]. It was also observed that the values of $E_{a}$ were more significant than the corresponding values of $\Delta \mathrm{H}$ showing that the corrosion process involves the evolution hydrogen, which is associated with a decrease in the total reaction volume [39, 48, 49]. Moreover, the average value of the difference between activation energy and heat of adsorption is $2.64 \mathrm{~kJ} / \mathrm{mol}$, which is approximately equal to 
the average value of RT $(2.61 \mathrm{~kJ} / \mathrm{mol})$ and agrees with the works of Bhat and Alva [50].

\subsubsection{Free energy of adsorption $\left(\Delta G_{\text {ads }}\right)$}

The calculated values of free energy of adsorption, $\Delta \mathrm{G}_{\mathrm{ads}}$ obtained using Eq. (9) [51] are presented in Table 5.

$\Delta \mathrm{G}_{\mathrm{ads}}=-\mathrm{RT} \ln \left(\frac{55.5 \theta}{\mathrm{C}(1-\theta)}\right)$

where $\theta$ is the degree of surface coverage, $C$ is the concentration of the inhibitors in $\mathrm{g} / \mathrm{L}, \mathrm{R}$ is the universal gas constant, and $\mathrm{T}$ is the absolute temperature. From the studies, negative values of $\Delta G_{\text {ads }}$ lower than $-20 \mathrm{~kJ} \mathrm{~mol}^{-1}$ were obtained, indicating the stability of the adsorbed PMS on the galvanized steel surface and the spontaneity of the corrosion inhibition process. Also, the values of $\Delta G_{\text {ads }}$ obtained are in line with electrostatic behaviour exhibited by the interaction between the PMS species and the charge on the galvanized steel surface, which indicates physical adsorption $[52,53]$. It was also observed that increase in temperature resulted in less negative values of $\Delta G_{\text {ads }}$ which suggests spontaneous reaction via physical adsorption and also an indication of chemical adsorption if immersion time is increased as reported by Ostovari et al. [54]. The observed physical adsorption with higher inhibitor concentration is as a result of the reduced molecular motion arising from increased viscosity of the system. Hence, the reduction in $\Delta G_{\text {ads }}$ at high concentration of $P M S$ inhibitor shows that there was desorption of the adsorbed inhibitor molecules due to instability arising from mere mechanical screening of the steel surface which is in line with reports by Hussin and Kassim [55].

\subsubsection{Mechanism of inhibition}

The inhibition efficiency of PMS corrosion inhibitor against the corrosion of galvanized steel in $1 \mathrm{M} \mathrm{HCl}$ can be explained on the basis of the number of adsorption sites, their charge density, molecular size, mode of interaction with the metal surface and the ability to form a metallic complex. In an inhibited system, active dissolution of the galvanized steel interface rapidly diminishes as the inhibitors molecules are being adsorbed on the metal surface blocking either the anodic or cathodic reaction or both $[24,56,57]$.

\section{Conclusion}

From this study, it was confirmed that the
1. Physical modification of starch effected changes as observed from the FTIR spectra.

2. The physically modified starch behaved as corrosion inhibitor of galvanized steel in acidic solutions with the protection level dependent on time, concentration and temperature, increasing with increase in concentration and decreasing with increase in time of immersion and temperature of the system.

3. Polarization measurements carried out in the presence of PMS revealed that the corrosion current decreased significantly with increasing concentration of the inhibitor, $\mathrm{E}_{\text {corr }}$ values indicates that both the cathodic and anodic partial reactions were inhibited by the PMS inhibitor with predominant cathodic effect.

4. The adsorption mode of PMS on the corroding galvanized steel surface best fitted Langmuir adsorption isotherm.

5. The trend of inhibition efficacy with temperature and calculated values of activation energy supported the proposed adsorption mechanism as well as the mechanism of corrosion inhibition of galvanised steel using PMS which was attributed to the chemical constituents of modified structure of starch.

These facts prove that this biopolymer could be used as a potential commercial product in the control of corrosion in acidic media systems, encouraging the use of compounds based on the green values.

Acknowledgement The authors are grateful to the Electrochemistry and Materials Science Research Laboratory, Department of Chemistry, Federal University of Technology, Owerri, Nigeria, for the assistance received in making this work successful.

\section{Compliance with ethical standard}

Conflict of interest The authors declare that they have no conflict of interests.

\section{References}

1. Mclntyre JF, Brent RJ (2000) Tendencies of the pretreatment technology in next millennium. Pinturas y Acabadosind 42(261):36-44

2. Buchheit RG, Mamidipally SB, Schmutz P, Guan H (2002) Active corrosion protection in Ce-modified hydrotalcite conversion coatings. Corrosion 58(1):3-14

3. Mobin M, Khan MA, Parveen M (2011) Inhibition of mild steel corrosion in acidic medium using starch and surfactants additives. J Appl Polym Sci 121:1558-1565

4. Sharmin E, Ahmad S, afar F (2012) Renewable resources in corrosion resistance. In: Dr Shih (ed). Corrosion Resistance, InTech, www.intechopen.com/books/corrosion-resistance/renewableresources-in-corrosion-resistance. Accessed 25 May 2015

5. Rani BEA, Basu BBJ (2012) Green inhibitors for corrosion protection of metals and alloys: an Overview. Int J Corros 38:105-120 
6. Umoren SA, Banera MJ, Alonso-Garcia T, Gervasi CA, Mirifico MV (2013) Inhibition of mild steel corrosion in $\mathrm{HCl}$ solution using chitosan. Cellulose 20:2529-2545

7. Rosliza R (2012). Improvement of corrosion resistance of aluminium alloy by natural products, Corrosion Resistance, $\mathrm{Dr}$ Shih (Ed.), ISBN: 978-953-51-0467-4, InTech. pp 377-396

8. Rajeswari V, Kesavan D, Gopiraman M, Viswanathamurthi $P$ (2013) Physicochemical studies of glucose, gellan gum, and hydroxypropyl cellulose-inhibition of cast iron corrosion. Carbohyd Polym 95:288-294

9. Ochoa N, Marisela B, Sancristóball J, Balsamo V, Albornoz A, Joaquin L et al (2013) Modified cassava starches as potential corrosion inhibitors for sustainable development. Mater Res 16:1556-1565

10. Oguzie EE (2004) Influence of halide ions on the inhibitive effect of congo red dye on the corrosion of mild steel in sulphuric acid solution. Mater Chem Phys 87:212-217

11. Rajendran S, Sridevi SP, Anthony N, Amairaj AJ (2005) Corrosion behaviour of carbon steel in polyvinyl alcohol. Anti Corros Methods Mater 52:102-107

12. Oguzie EE, Njoku VO, Enenebeaku CK, Akalezi CO, Obi C (2008) Effect of hexamethylpararosaniline chloride (crystal violet) on mildsteel corrosion in acidic media. Corros Sci 50:3480-3486

13. Mehdi JJ, Mohamadsaeed Y, Ashkan M (2014) Preparation of cold water- soluble potato starch and its characterization. $J$ Food Sci Technol 51:601-605

14. Alcázar-Alay SC, Meireles MAA (2015) Physicochemical properties, modifications and applications of starches from different botanical sources. Food Sci Technol. https://doi. org/10.1590/1678-457X.6749

15. Moorthy SN (2002) Physicochemical and functional properties of tropical tuber starches: a review. Starch 54(12):559-592

16. Burrell MM (2003) Starch: the need for improved quality or quantity-an overview. J Exp Bot 54:451-456

17. Lopez OV, Zaritzky NE, Garcia MA (2010) Physicochemical characterisation of chemically modified corn starches related to rheological behaviour, retrogradation and film forming capacity. J Food Eng 100(1):160-168

18. Fiedorowicz M, Tomasik P, Lii CY (2001) Degradation of starch by polarised light. Carbohyd Polym 45:79-87

19. Liang Y, Zhang BS, Yang LS, Gao DW (2004) Chemical reaction activity of tapioca starch with non-crystallized granule state. J Zhengzhou Inst Technol 25:9-13

20. Zhang DQ, Xie B, Gao LX, Joo HG, Lee KY (2011) Corrosion inhibition of ammonium molybdate for AA6061 in NaCl solution and its synergestic effect with calcium gluconate. Surf Interface Anal 44:78-83

21. Liu Y, Himmelsbach DS, Barton FE (2004) Two-dimensional Fourier transform Raman correlation spectroscopy determination of the glycosidic linkages in amylose and amylopectin. Appl Spectrosc 58:745

22. Wang YJ, Truong VD, Wang L (2003) Structures and rheological properties of corn starch as affected by acid hydrolysis. Carbohyd Polym 52(3):327-333

23. Nwanonenyi SC, Madufor IC, Chukwujike IC, Arinze VC (2016) Experimental and theoretical studies of the inhibitive behaviour of millet starch on the corrosion of aluminium in the sulphuric acid environment. Int J Eng Technol 8:1-13

24. Bello M, Ochoa N, Balsamo V, López-Carrasquero F, Coll S, Monsalved A et al (2010) Modified cassava starches as corrosion inhibitors of carbon steel. An electrochemical and morphological approach. Carbohyd Polym 82(3):561-568

25. Othman NK, Salleh EM, DasukiZabdLazim AM (2018) Dimethyl sulfoxide treated starch of dioscorea hispida as a green corrosion inhibitor for low carbon steel in sodium chloride medium.
Corros Inhibitors Princ Recent Appl. https://doi.org/10.5772/ intechopen.73552

26. Xianghong $L$, Shunduan D, Tong $L$, Xiaoguang $X$, Guanben D (2019) Cassava starch ternary graft copolymer as a corrosion inhibitor for steel in HCL solution. J Mater Res Tech. https://doi. org/10.1016/j.jmrt.2019.12.050

27. Li XH, Deng S, Fu H, Li YX (2017) Corrosion inhibition of cataionic cassava starch graft copolymer for steel in $\mathrm{HCl}$ solution. Fine Chem 34:319-325

28. Xianghong $L$, Shunduan $D$, Tong $L$, Xiaoguang $X$, Guanben $D$ (2018) Cassava starch sodium allylsulfonate acryl amide graft copolymer as an effective inhibitor of aluminium corrosion in $\mathrm{HCl}$ solution. J Taiwan Inst Chem Eng 86:252-269

29. Li X, Deng S (2015) Cassava starch graft copolymeras an ecofriendly corrosion inhibitor for steel in $\mathrm{H}_{2} \mathrm{SO}_{4}$. Korean $\mathrm{J}$ Chem Eng 32(11):2347-2354

30. Nwanonenyi SC, Madufor IC, Uzoma PC, Chukwujike IC (2016) Corrosion inhibition of Mild Steel in sulphuric acid environment using millet starch and potassium. Int Res J Pure Appl Chem 12(2):1-15

31. Della Valle G, Vergnes B (1995) The extrusion behaviour of potato starch. Carbohyd Polym 28(3):255-264. https://doi. org/10.1016/0144-8617(95)00111-5

32. Kizil J, Seetharaman K (2002) Characterization of irradiated starches by using FT-Raman and FTIR spectroscopy. J Agric Food Chem 50:3912

33. Kacurakova M, Capeka P, Sasinkova V, Wellner N, Ebringerova A (2000) FT-IR study of plant cell wall model compounds: pecticpolysaccharides and hemicelluloses. Carbohyd Polym 43:195-203

34. Fang JM, Fowler PA, Sayers C, Williams PA (2004) The chemical modification of a range of starches under aqueous reaction condition. Carbohyd Polym 55:283-289

35. Majzoobi M, Radi M, Farahnaky A, Jamalian J, Tongdang T, Mesbahi G (2011) Physicochemical properties of pre-gelatinized wheat starch produced by a twin drum drier. J Agric Sci Technol 13(2):193-202

36. Li W, Cao F, Fan J, Ouyang S, Luo Q, Zheng J, Zhang G (2014) Physically modified common buckwheat starch and their physicochemical and structural properties. Food Hydrocolloids 40:237-244

37. Oguzie EE (2005) Inhibition of acid corrosion of mild steel by Telfariaoccidentalis extract. Pigment Resin Technol 34:321-326

38. Vracar LM, Drazic DM (2002) Adsorption and corrosion inhibitive properties of some organic molecules on iron electrode in sulfuricacid. Corros Sci 44:1669-1680

39. Nwanonenyi SC, Obasi HC, Oguzie EE, Chukwujike IC, Anyiam CK (2017) Inhibition and adsorption of polyvinyl acetate (PVAC) on the corrosion of aluminium in sulphuric and hydrochloric acid environment. J Bio Tribo Corros 3:53

40. Satapathy AK, Gunasekaran G, Sahoo SC, Amit K, Rodrigues PV (2009) Corrosion inhibition by Justiciagendarussa plant extract in hydrochloric acid solution. Corros Sci 51(12):2848-2856

41. Hassan HH, Abdelghani E, Amin MA (2007) Inhibition of mild steel corrosion in hydrochloric acid solution by triazole derivatives; part 1; polarisation and EIS studies. Electrochimica Acta 52(22):6359-6366

42. Eduok UM, Khaled MM (2014) Corrosion protection of steel sheets by chitosan from shrimp shells at acid $\mathrm{pH}$. Cellulose 21:3139-3143

43. Hazwan MH, Kassim MJ (2010) The corrosion inhibition andadsorption behaviour of Uncariagambir extract on mild steel in $1 \mathrm{MHCl}$. Mater Chem Phys. https://doi.org/10.1016/j.match emphys.2010.10.032

44. Arukalam IO, ljomah NT, Nwanonenyi SC, Obasi HC, Aharanwa BC, Anyanwu PI (2014) Studies on acid corrosion of aluminium 
by a naturally occurring polymer (Xanthan gum). Int J Sci Eng Res 5:663-673

45. Popova A, Sokolova E, Raicheva S, Christov M (2003) AC and DC study of the temperature effect on mild steel corrosion in acid media in the presence of benzimidazole derivatives. Corros Sci 45(1):33-58

46. Ebenso EE (2003) Effect of Halide ions on the corrosion inhibition of mild steel in $\mathrm{H}_{2} \mathrm{SO}_{4}$ using methyl red. Bull Electrochem 19(1):209-216

47. Noor EA, Al-Moubaraki AH (2008) Thermodynamic study of metal corrosion and inhibitor adsorption processes in mild steel/1-methyl-4 [4'(-X)-styrylpyridinium iodides/hydrochloric acid systems. Mater Chem Phys 110(1):145-154

48. Shukla SK, Ebenso EE (2011) Corrosion Inhibition, Adsorption behaviour and thermodynamic properties of streptomycin on mild steel in hydrochloric acid medium. Int J Electrochem Sci 6(8):3277-3291

49. Dahmani M, Et-Touhami A, Al-Deyab SS, Hammouti B, Bouyanzer A (2010) Corrosion inhibition of C 38 steel in $1 \mathrm{M} \mathrm{HCl}$ : a comparative study of black pepper extract and its isolated piperine. Int J Electrochem Sci 5(8):1060-1069

50. Bhat Jl, Alva VD (2011) Inhibition effect of miconazole nitrate on the corrosion of mild steel in hydrochloric acid medium. Int J Electrochem 3:343

51. Hamdy A, El-Gendy NS (2013) Electrochemical studies for corrosion inhibition of carbon steel by henna extract in acid medium. Egyptian Petroleum Research Institute, Nasr City

52. John S, Joseph B, Balakrishnan KV, Aravindakshan KK, Joseph A (2010) Electrochemical and quantum chemical study of
4-[(E)-[(2,4-dihydroxy phenyl) methylidine] amino]-6-methyl-3-sulphanylidine-2,3,4,5-tetrahydro-1,2,4-triazin-5-one [DMSTT]. Mater Chem Phys 123:218-224

53. Umoren SA, Ogbobe O, Ebenso EE (2006) Synergistic inhibitionof aluminium corrosion in acidic medium by gum arabic and halideions. Trans SAEST 41:74-81

54. Ostovari AH, Peikari SM, Shadizadeh SR, Hashemi SJ (2009) Corrosion inhibition of mild steel in $1 \mathrm{M} \mathrm{HCl}$ solution by henna extract: a comparative study of the inhibition by henna and its constituents (lawsone, gallic acid, a-D-glucose and tannic acid). Corros Sci 51:1935-1949

55. Hussin MH, Kassim MJ (2010) The corrosion inhibition and adsorption behaviour of Uncariagambir extract on mild steel in $1 \mathrm{M} \mathrm{HCl}$. Mater Chem Phys 125(3):461-468

56. Obot IB, Obi-Egbedi NO (2010) Adsorption properties and inhibition of mild steel corrosion in sulphuric acid solution by ketoconazole: experimental and theoretical investigation. Corros Sci 52:198-204

57. Mistry BM, Patyl NS, Sahoo S, Junhari S (2012) Experimental and quantum chemical studies on corrosion inhibition performance of quinoline derivatives for MS in $1 \mathrm{M} \mathrm{HCl}$. Bull Mater Sci $35: 459-469$

Publisher's Note Springer Nature remains neutral with regard to jurisdictional claims in published maps and institutional affiliations. 